\title{
An empirical study to investigate the effects of thinking styles on emotional intelligence: A case study of Jihad Agriculture Organization of east Azerbaijan province
}

\author{
Hassan Darvish $^{\mathrm{a}}$ and Habibeh Ayagh ${ }^{\mathrm{b}^{*}}$
}

${ }^{a}$ Assistant professor, Department of Economic, Management and Accounting, Payame Noor University 19395-4697,Tehran, Iran ${ }^{b}$ Master Student, Department of Public Administration, Payame Noor University, Tehran, Iran

\section{H R O N I C L E A B S T R A C T}

Article history:

Received October 14, 2012

Received in revised format

24 December 2012

Accepted 5 January 2013

Available online

January 182013

Keywords:

Emotional intelligence

Thinking style

Agricultural industry

\begin{abstract}
An empirical study to investigate the effects of thinking styles on emotional intelligence among employees of agriculture industry in east Azerbaijan province. The proposed study uses a standard thinking style questionnaire originally developed by Sternberg and Wagner (1992) [Sternberg, R. J., \& Wagner, R. K. (1992). Thinking styles inventory. Unpublished test, Yale University]. There are 716 employees working for this agriculture-based unit and the study uses random sampling technique and chooses 255 employees for this study. Cronbach alpha has been used to verify the overall questionnaire and different tests such as Kolmogorov-Smirnov and Pearson correlation test are used to examine different hypotheses of this survey. The results indicate there is positive and meaningful relationship between thinking style and emotional intelligence. We can also confirm that four thinking style’s components including functions, levels, scope and learning have meaningful impact on emotional intelligence when the level of significance is five or even one percent. However, forms did not have any meaningful impact on emotional intelligence.
\end{abstract}

\section{Introduction}

Emotional intelligence has been considered as one of the key components, which could significantly influence organizations. There are many studies to find out how we can increase the level of emotional intelligence among employees. Saeidipour et al. (2012), for instance, studied the effect of emotional intelligence on organizational learning staff in a case study of Jihad Agriculture Organization of Isfahan. Lotfi et al. (2011) performed an investigation on emotional intelligence survey among master students of Shahid Beheshti University who attained the grades one to nine (19) in entrance exam. Their results showed that there was a positive correlation between students' grade of entrance exam and all dimensions of emotional intelligence.

*Corresponding author. Tel: +989122655034

E-mail addresses: ayaggh5@yahoo.com (H. Ayagh)

(C) 2013 Growing Science Ltd. All rights reserved. doi: 10.5267/j.msl.2013.04.014 
Karimi et al. (2012) performed a comparative study on emotional intelligence and cognitive between successful and unsuccessful entrepreneurs. They adopted a standard test, which included 133 questions and distributed it between two groups of successful and unsuccessful entrepreneurs in province of Sistan and Balochestan located in south west of Iran. The results of the ANOVA test when the level of significance was five percent revealed that emotional intelligence could substantially impact on the success of entrepreneurs.

Iravani and Mosavi (2012) presented a social work study on emotional intelligence among different groups of people how were addicted to drugs. The study distributed a questionnaire among three groups consists of 117 questions and 15 scales. The first group of the survey was under communitybased treatment, the second group included the people who were members of a community with unknown identification and the third group covered outpatient patient who received medication. The results of their survey indicated that the level of emotional intelligence among the first group of the study was much more than the other groups. Ivan (2011) investigated the relative importance of popularity, rational thinking style and nonverbal sensitivity to achieve academic success. In other words, they investigated weather popularity in the academic related networks and the way students were proccessing information - rational or experiential predict their final grades.

Yu and Chen (2012) investigated the relationship between thinking styles and preferred teacher interpersonal behavior among Hong Kong students. They reported that Type I global and liberal styles positively and negatively forecasted student-centered teacher interpersonal behavior respectively, while Type I legislative and judicial styles negatively and positively forecasted teachercentered interpersonal behavior respectively. Type II conservative and executive styles positively forecasted teacher-centered interpersonal behavior, while Type II executive and conservative styles positively and negatively forecasted student-centered interpersonal behavior respectively.

Nastas and Sala (2012) performed an investigation on relationship between adolescents' emotional intelligence and parental styles. They reported that the development level of emotional intelligence was impacted by the five parental styles including authoritarian, dictatorial, permissive, democratic and rejecting / neglecting. Kim and Agrusa (2011) studied hospitality service employees' coping styles by studying the role of emotional intelligence, two basic personality traits, and sociodemographic factors.

Gheze Soflu et al. (2011) made a comparison between emotional intelligence and mental skills and their relationship with the experience of individual and team sport fields' athletes in super league of Golestan Township. In order to evaluate mental skills of subjects, they used Thomas's test of strategic performance (TOPS) that measures 8 micro scales, for evaluating emotional intelligence. They reported that there was a significant difference among these micro scales of self talk and mental imaging and negative thinking among team and individual sport athletes. In addition, in emotional intelligence micro scales, there was a significant difference in some micro scales including self management, self motivation and social skills, but no significant difference was reported in self awareness and empathy micro scales.

Noorbakhsh et al. (2010) examined the relationship between emotional intelligence and coping styles with stress in a sample of students. All participants completed the Emotional Intelligence Scale (EIS) and the Tehran Coping Styles Scale (TCSS). They reported that EI was positively associated with problem-focused and positive emotional focused coping styles, and negatively associated with negative emotional focused coping style. EI was supposed to impact coping strrategies through management and regulation of emotions, utilization and facilitation of emotions, and apprisal of emotions.

MacCann et al. (2011) examined the relationships between performance measures of emotional intelligence, coping styles, and academic achievement is sparse. In their study, the coping variables significantly mediated the relationship between emotion management and GPA. Problem-focused 
coping was a significant mediator and the results suggested that better educational outcomes might be achieved by targeting skills relating to emotion management and problem-focused coping.

\section{The proposed study}

The proposed study uses a standard thinking style questionnaire originally developed by Sternberg and Wagner (1992). The proposed study of this paper examines the relationship between thinking style and emotional intelligence. The main hypothesis of the survey is as follows,

Main hypothesis: There is a meaningful relationship between thinking style and emotional intelligence.

In our study, thinking style contains five components including functions, forms, levels, scope and leanings and this leads us to examine the following five sub-hypothese,

1. There is a meaningful relationship between thinking style, function, and emotional intelligence.

2. There is a meaningful relationship between thinking style, forms, and emotional intelligence.

3. There is a meaningful relationship between thinking style, levels, and emotional intelligence.

4. There is a meaningful relationship between thinking style, scope, and emotional intelligence.

5. There is a meaningful relationship between thinking style, learning, and emotional intelligence.

The proposed study of this paper uses the following regression analysis to examine different hypotheses of this survey.

$$
E I=\beta_{0}+\beta_{1} \text { Functions }+\beta_{2} \text { Form }+\beta_{3} \text { Levels }+\beta_{4} \text { Scope }+\beta_{5} \text { Learning }+\varepsilon,
$$

where $E I$ is the dependent variable and represents emotional intelligence, Functions, Form, Levels, Scope and Learning are independent variables. In addition, $\beta_{i}, i=1, \ldots, 5$ are coefficients to be estimated and $\varepsilon$ represents residuals.

There are 716 employees working for this agriculture-based unit, the study uses random sampling technique and uses the following formula to calculate the minimum number of sample size,

$$
n=\frac{N \times z_{\alpha / 2}^{2} \times p \times q}{\varepsilon^{2} \times(N-1)+z_{\alpha / 2}^{2} \times p \times q},
$$

where $N$ is the population size, $p=1-q$ represents the yes/no categories, $z_{\alpha / 2}$ is CDF of normal distribution and finally $\varepsilon$ is the error term. Since we have $p=0.5, z_{\alpha / 2}=1.96$ and $N=716$, the number of sample size is calculated as $n=250$. Cronbach alpha has been used to verify the overall questionnaire and different tests such as Kolmogorov-Smirnov and Pearson correlation test are used to examine different hypotheses of this survey. In our study, $78.8 \%$ of the participants were male and $21.2 \%$ of them were female. Fig. 1 demonatrates details of their personal characteristics of the surveyed people in terms of age while Fig. 2 presents details of our participants in terms of years of educations and Fig. 3 shows their job experiences. 


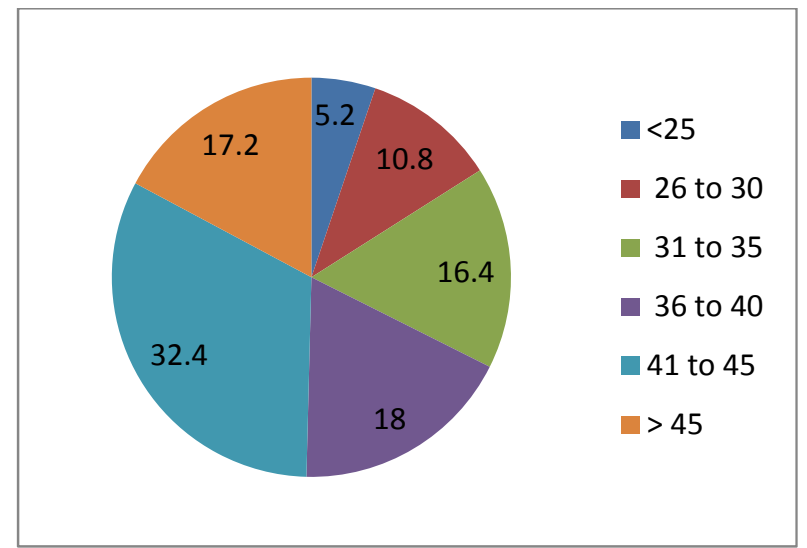

Fig. 1. Diversity of age

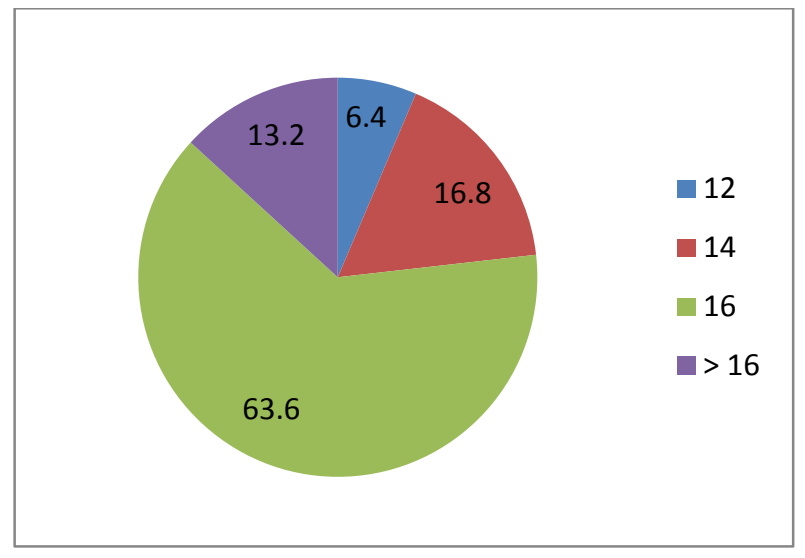

Fig. 2. Years of educations

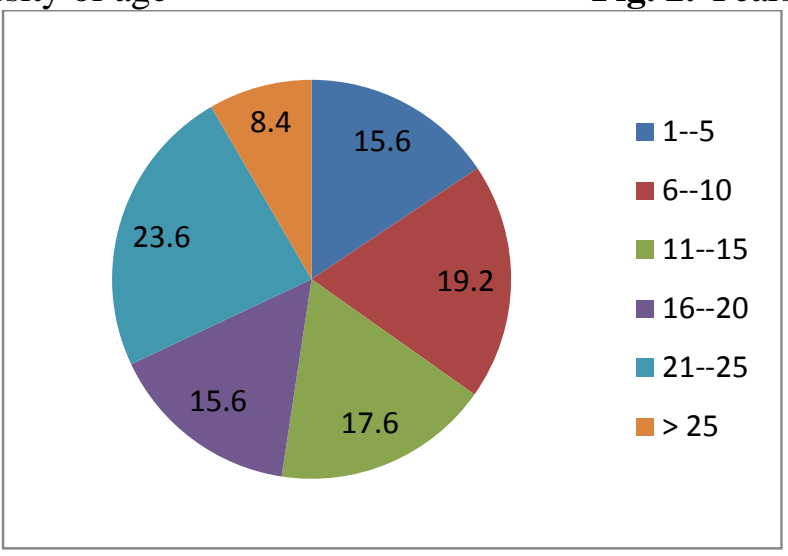

Fig. 3. Years of job experiences

Sternberg and Wagner's (1992) thinking style questionnaire consists of five categories including functions, forms, levels, scope and leanings. Table 1 demonstrates destils of some basic statsitics on five categories of the questionnaire.

\section{Table 1}

The summary of basic statistics on thinking style and testing normality for all variables

\begin{tabular}{lccccccc}
\hline Perspective & Min & Max & Mean & Standard dev. & Sig. & Level of significance & Results \\
\hline Functions & 2.67 & 6.56 & 4.9103 & 0.73254 & 0.262 & 0.05 & Normal \\
Forms & 2.92 & 6.83 & 4.9335 & 0.75078 & 0.236 & 0.05 & Normal \\
Levels & 2.33 & 6.33 & 4.2572 & 0.81573 & 0.066 & 0.05 & Normal \\
Scope & 1.83 & 6.17 & 4.1337 & 0.74583 & 0.091 & 0.05 & Normal \\
Learning & 2.67 & 6.33 & 4.2922 & 0.62978 & 0.136 & 0.05 & Normal \\
Emotional Intelligence & 1.68 & 3.52 & 2.6196 & 0.35574 & 0.971 & 0.05 & Normal \\
\hline
\end{tabular}

As we can observe from the results of Table 1, the maximum point belongs to forms followed by functions while the minimum points are devoted to scope and levels. In terms of mean, forms maintained the highest mean while scope receives the minimum mean. The other observation is that all variables are normally distributed when the level of significance is five percent. Since we plan to use regression analysis to examine different hypotheses, we need to make sure there is no strong correlations among independent variables using VIF test and Table 2 shows details of our test. As we can observe from the results of Table 2, all tolerances are greater than 0.1 and all VIF values are less than 10, which means there is no lieanrity among independent variables when the level of significance is five percent. In addition, the results of Pearson correlation test indicate that there are some positive and meaningful correlation ratios between emotional intelligence and different style of thinking's perspective. 
Table 2

The summary of testing colinearity as well as Pearson correlation test

\begin{tabular}{lccc}
\hline Perspective & Tolerance & VIF & Emotional Intelligence \\
\hline Functions & 0.481 & 2.078 & 0.495 \\
Forms & 0.440 & 2.275 & 0.523 \\
Levels & 0.644 & 1.553 & 0.504 \\
Scope & 0.639 & 1.565 & 0.535 \\
Learning & 0.829 & 1.206 & 0.341 \\
\hline
\end{tabular}

\section{The results}

In this section, we present details of stepwise regression analysis for the data we have gathered in our survey. Table 3 demonstrates the summary of our findings.

Table 3

The summary of regression analysis between emotional intelligence and thinking style

\begin{tabular}{lccccc}
\hline Perspective & P-value & t-value & Standard value & Non-Standard value & Results \\
\hline Functions & 0.001 & 3.220 & 0.214 & 0.104 & Effective \\
Forms & 0.106 & 1.621 & 0.113 & 0.054 & Non-effective \\
Levels & 0.000 & 4.142 & 0.239 & 0.104 & Effective \\
Scope & 0.000 & 4.583 & 0.265 & 0.126 & Effective \\
Learning & 0.003 & 2.980 & 0.151 & 0.085 & Effective \\
\hline
\end{tabular}

Based on the results of Table 3, we can confirm that four thinking style's components including functions, levels, scope and learning have meaningful impact on emotional intelligence when the level of significance is five or even one percent. However, forms did not have any meaningful impact on emotional intelligence.

\section{Conclusion}

In this paper, we have presented an empirical study to investigate the relationship between thinking style and emotional intelligence. The proposed study of this paper used a Sternberg and Wagner's questionnaire to examine different hypotheses of thus survey. The results of the survey have concluded that four thinking style's components including functions, levels, scope and learning had meaningful effect on emotional intelligence when the level of significance was five or even one percent. However, forms did not have any meaningful impact on emotional intelligence.

\section{References}

Gheze Soflu, H., Esfahani, N., \& Assadi, H. (2011). The Comparison of Emotional Intelligence and Psychological Skills and Their Relationship with Experience among Individual and Team Athletes in Superior League. Procedia - Social and Behavioral Sciences, 30, 2394-2400.

Iravani, M.R., \& Mosavi, S.E. (2012). A social work study on emotional intelligence among different groups of people how are addicted to drugs. Management Science Letters, 2(1), 119-124.

Ivan, L. (2011). The importance of popularity, rational thinking style and nonverbal sensitivity to achieve academic success. Procedia - Social and Behavioral Sciences, 29, 725-734.

Karimi, P., Kloshani, M., \& Bakhshizadeh, A. (2012). A comparative study on emotional intelligence and cognitive between successful and unsuccessful entrepreneurs. Management Science Letters, 2(6), 2071-2076.

Kim, H.J., \& Agrusa, J. (2011). Hospitality service employees’ coping styles: The role of emotional intelligence, two basic personality traits, and socio-demographic factors. International Journal of Hospitality Management, 30(3), 588-598. 
Lotfi, S., Ayazi, M., \& Agheli-Nejad, M.A. (2011). Emotional intelligence survey in master students of Shahid Beheshti University who attained the grades one to nine (1-9) in entrance exam. Procedia - Social and Behavioral Sciences, 30, 826-829.

MacCann, C., Fogarty, G.J., Zeidner, M., \& Roberts, R.D. (2011). Coping mediates the relationship between emotional intelligence (EI) and academic achievement. Contemporary Educational Psychology, 36(1), 60-70.

Nastas, L.E., \& Sala, K. (2012). Adolescents' emotional intelligence and parental styles. Procedia Social and Behavioral Sciences, 33, 478-482.

Noorbakhsh, S.N., Besharat, M.A., \& Zarei, J. (2010). Emotional intelligence and coping styles with stress. Procedia - Social and Behavioral Sciences, 5, 818-822.

Saeidipour, B., Akbari, P., Marati Fashi, M.A. (2012). Study the effect of emotional intelligence on organizational learning staff, Case study: Jihad Agriculture Organization of Isfahan. Management Science Letters, 2(7), 2501-2510.

Sternberg, R. J., \& Wagner, R. K. (1992). Thinking styles inventory.Unpublished test, Yale University.

Yu, T.M., \& Chen, C. (2012). Thinking styles and preferred teacher interpersonal behavior among Hong Kong students. Learning and Individual Differences, 22(4), 554-55. 